\title{
VIDA Y PRESENCIA DE GIL VICENTE
}

\author{
Ramón Zapata Acosta
}

La obra de un escritor nos induce a conocer su vida y a ubicar ésta en el tiempo. Nos interesa conocer al hombre, no sólo sobre el pedestal que le ha erigido la grandeza, sino moviendose sobre la tierra, común a todos los humanos. Los ojos del entendimiento lo quieren como criatura viva, no como un nombre más en el mundo de las ideas.

Al acercarnos a Gil Vicente para escrutar su vida, se nos escapa a veces y otras se nos presenta en un claroscuro.

1. Identificación. - Un problema surge.

¿Era Gil Vicente poeta y dramaturgo, el mismo Gil Vicente orífice y mestre da balança de la Casa de la Moneda de Lisboa?

El problema quiere complicarse aún más. Bell, el gran crítico inglés y asiduo investigador vicentino, nos habla de la oscuridad del caso y nos dice:

"...the known existence of half a dozen contemporary Gil Vicentes maks research a risky operation. There was a page (1475) and an escudeiro (1482) of João II, an official at Santarem, a Santarem, carpenter (1500), there was a Gil Vicente in India in 1513 in 1513 Alfonso Albuquerque writes of the son of Gil Vicente in India] and Gil Vicente goldsmith at Lisbon." '

(1) Aubrey F. G. Bell, Portuguese Literature (Oxford, The Clarendon Press, 1929) pág. 108. 
Menéndez y Pelayo declara que se sabe poco de sua vida "exceptuando lo que consta en las rúbricas de sus propias obras dramáticas." "-

Añade que un genealogista, Cabedo de Vasconcellos, "dice que Gil Vicente fue maestro de retórica del rey D. Manuel;"; que

"en 1482 un Gil Vicente. que nos sabemos a punto fijo si es el maestro. aparece designado ya como escudero de Juan II, y en 1492 escribía versos para el proceso satírico de Vasco Abul, que puede verse en el Cancionero [de Resende] tantas veces citado."

Tomando como base lo que refiere el Gil Vicente poeta dramático en su Floresta de Engaños, de 1536, "que tenía sesenta $y$ seis años," no cree

"que pueda ser la misma persona un Gil Vicente que ya en 1475 era moço de estribeira del príncipe D. Juan, en 1482 porteiro dos Contos do Almoxarifado de Beja, en cuya ciudad le hizo merced de algunos bienes D. Juan II en 1485, y finalmente en 1491 porteiro dos Contos de Mestrado de Aviz (documentos de la Torre do Tombo, publicados por Teófilo Braga, que sostiene la identidad de éste y de todos los Gil Vicentes posibles.)"

Simplificando, sin embargo. nos queda sólo la interrogación expuesta al principio. Menéndez y Pelayo no cree que poeta y orifice sean la misma persona, que el "autor de la custodia de Belem y otras piezas artisticas memorables" y el fino lírico se resuelvan en uno. Razona diciendo que si tal fuese el caso es de extrañar que ni sus obras ni sus contemporáneos lo revelaran. ${ }^{8}$ Prosigue:

"Sólo un genealogista muy posterior y no muy acreditado, Cristobal Alão de Morães, en un manuscrito de 1667 dice que Gil Vicente, el poeta, era hijo de Martín Vicente, orifice de plata en Guimaraens, pero a su hijo no le atribuye tal oficio, sino el de compositor de autos."

(2) Marcolino Menéndez y Peleyo, Antologia de peofas liries eastellznos (XIV Vols., Madrid, Librería de Hernando y $C$, s. s., VII\}, pógs. CLXY - CLXVI.

(3) Ibid., pág. CLXVI, Nota 2.

(4) Ibid., pág. CLXVII.

(5) Loc. cit., Nota 1.

(6) Loc. cit.

(7) Ibid., pág. $C L X V \mid$.

(8) Loc. cit.

(9) Loc. cit., Nota 2. 
En la actualidad los críticos están acordes en que Gll Vicente fue poeta y orífice a la vez. Valbuena Prat afirma que esto se creyó en el siglo XIX, se discutió a fines del mismo y se tiene hoy por cierto. "Así se dan la mano los autos religiosos y la custodia de Belem", dice. ${ }^{10}$ De Figueiredo, crítico portugués, esevera que fue "orfebre de la reina don̄a Leonor, viuva de Juan II" y "mestre da balança de la Casa de la Moneda de Lisboa;" " que entró en la Casa de la Moneda en 1513, "según la real carta que existe todavía, y cuya aparición vino a confirmar la identificación del poeta con el orfebre por tener en la parte superior la siguiente anotación, trazada por mano contemporánea: Gil Vicente trovador, mestre da balança. En 1506 concluyó la célebre custodia de los Jerónimos, labrada con el oro de los primeros tributos traídos de Oriente por Vasco da Gama."'2

Northup, ${ }^{13}$ Bell. $^{14}$ Carolina Michaëlis de Vasconcellos ${ }^{16}$ y Dámaso Alonso ${ }^{16}$ están de acuerdo con lo mismo. Bell nos revela que las probabilidades son muy convincentes; que no se puede creer en el Vizconde Sánches de Baena (1822 - 1909) quien concluye triunfalmente que los Gil Vicente eran tío y sobrino, ni en Trófilo Braga, quien dice que eran primos. ${ }^{17}$ Nota que el poeta hace mención frecuente a oro, joyas, zafiros, perlas, rubies, en sus comedias, lo mismo que tiene cariño al convento de Thomar y al Hospital de Todos los Santos, donde el orifice era inspetor. Aun en lo técnico hay relación: "The goldsmith in the Farça dos Almocreves uses the technical word bastiães".18 Añade que el poeta estuvo en la Casa de la Moneda de 1513 a 1518 como mestre de balança, y que luego dedicó todo su esfuerzo a las letras. Objeta a Menéndez y Pelayo diciendo que las obras producidas por el poeta son esencialmente de un artista y que poseen una plasticidad rara en la literatura portuguesa. Comenta que Gil Vicente no era famoso poeta en 1503 cuando empezó lá custodia,

(10) Angel Valbuena Prat, Historia de la literafura española (1I Vols, Barcelona, Gustovo Gili, 1937, 1) pógs. 379-380.

(11) Fidelino de Figueiredo, Historia de la literatura portuguess (Traducción del Marquás de Lozoya, Barcelona, Editorlal Labor, S. A., 1927), p6g. 48.

(12) Loc, cit.

(13) Geerge T. Northup, An Introduction to Spanish Literalure (Fifth Impression, Chicsgo, The University of Chicago Press, 1934), 234.

(14) A. F. G. Bell, Op. cit., pp. 11.113 .

(15) Carolina Michael's de Vasconcellos, Autos Portugueses do Gil Vicente $y$ de Escuela Vi. cantina. Edición facsímil del Centro de Estudios Históricos con una introducción por... (Madrid, Imprents de los Sucesores do Hernands, 1922), pbg. 122.

(16) Dómaso Alonso, Poesía española. Antologia. Poesía de la Edad Modia y poesía do lipo tradicional. So'ección, notas y vocabulario, por ... (Madrid, Signo, 1935), p6́g. 542.

(17) A. F. G. Bell, Op., cil., p. 111. No hem:s podido censultar a Brags para eselarecer una duda: Menéndez y Pelayo escribe que Braga decía quo les Gil Vientes eram uno mismo y Bell dice que el critico portugués cencluye que eran primss.

(18) Loc. cif., Nots 2. 
y que el énfasis se dio más tarde a su poesía y no a su labor de orífice. ${ }^{19}$

¿Cuál es nuestra posición? Creemos que Gil Vicente pudo ser poeta y orífice a la vez, un genio de la misma clase de Leonardo da Vinci. La anotación en la carta a que se refiere Figueiredo - "Gil Vicente trovador, mestre da balança" nos parece convincente.

2. Su patria. - No se sabe con exactitud el sitio en que naciera nuestro biografiado. Menéndez y Pelayo, ${ }^{20}$ Valbuena Prat, ${ }^{2 !}$ Hurtado Palencia22 y Marques Braga ${ }^{23}$ creen que pudo haber sido en Guimaraens, Lisboa o Barcellos.

Bell, quien estudia a conciencia este asunto, indica en su Portuguese Liberature que Vicente “... sarcastically spoke of himself as the son of a pack-saddler and born at Pederneira (Extremadura)."24 Pero no pareciéndole cierto esto, continua: "He may have been son of Luis Vicente or Martín Vicente, 'said to have been a silversmith at Guimarães' (Minho)." "23 Nos informa que la autoridade en esto último es Cristoval Alão de Morrães en su manuscrito Pedatura Lusitana. de 1667; que este genealogista, según declara Castello Branco, 'era as vezes ignorante e outras vezes mal intencionado,' pero Alão de Moräes no dice que Gil naciera en Guimaraens. ${ }^{26}$ Otra posibilidad surge, anotada por Bell: "Pedro Poyares, Tractado em lonvor da villa de Barcellos (1672) says that Gil Vicente 'em tempo de D. João o terceiro poeta foi natural de Barcellos e andam algunas cousas suas impressas'." 27 Tomando peculiaridades linguísticas como base, el sabio investigador inglés insinúa que Gil Vicente pudo haber sido natural de Beira. ${ }^{28}$ Tal razonamiento nos parece discutible ya que una persona puede transladarse pequeña de su pueblo a otro sitio y adquirir los caracteres especiales de éste. En una crítica a O. de Prat, quien afirma que el poeta nació en Lisboa

(19) lbid. Pp. 112.113 .

(20) M. Men-ndez y Pelayo, lp. cit., pág. CLXVI.

(21) Angel Valbuena Praf, literatura dramática españala (Barcelona, Editorial Labor, 1930), póg. 52.

(22) Jusn Hurtado y Angel Genzález Palencia, Historia de la literatura española (3a ed. corregida y aumentada, Madrid, T'pografia de Archivos, 1932), pág. 345.

(23) Gil Vicente, Triunfo do Inverno (Editado por Marques Braga, Lisbos, Imprensa Nacional, 1934), págs. V.VI.

(24) A. F, G. Bell, Op. eit., pp. 108-100.

(25) Ibid., p. 109.

(26) Loc. cil., Nota 2.

(27) Loc. cit.

(28) Ibid., p. 109. Cita palabras propias de Beira. como nega, nego, abem, acajuso, algorrem, samicas, usadas por Gil Vicente; dice que no pucde arribuirse todo a la suposición de que beirazo es equivalente a rüstico y Beira a Buoefia, "for Beiru and the Serra da Estrella intrude constanly and indeed pervade his work. He shows personal knowledge of tho ccuntry, between Manteigas and Fundjo..." 
y conocia la lengua de Beira a través de informaciones dadas por provincianos que vivían en Lisboa, Bell afirma que "sigue siendo lo más probable que Gil Vicente naciera en una aldea o villa del norte de Portugal y fuera a Lisboa como iban tantos a fines del siglo XV en busca de fortuna.". En The Oxford Book of Portuguese Verse el mismo crítico dice del lusitano: "...born probably in the heart of Portugal (Beira or Minho)."30 Don Hermenegildo Giner de los Ríos, sin advertir el problema, se limita a mencionar a Barcellos. ${ }^{31}$

3. Fecha de su nacimiento. Corresponde um signo de interrogación a la fecha de su nacimiento. Casi todos los criticos están de acuerdo con que fue alrededor de 1465. Menéndez y Pelayo nos dice que por conjeturas se fija entre 1469 y $1470 .^{33}$ Estas conjeturas se basan en un pasaje de Floresta de Engaños, escrita en 1536, en la que el autor, como juez, confiesa que tiene ya sesenta y seis años Sobre esto nos aconseja Bell: "It is a method which might lead to comical results if further pressed in the case of Gil Vicente or other dramatists. Was Mello seventythree when he wrote the Fidalgo Aprendiz?"'34

En el Auto da Festa revela que tiene más de sesenta años: "He logo mui barregudo. E mais passa dos sesenta". ${ }^{35}$ No se conoce la fecha de este auto. Bell asegura que fue escrito antes de Templo de Apolo (1526) y lo coloca con probabilidades en 1525. Con esto lleva la fecha del nacimiento a cerca de1465. ${ }^{36}$ O. de Pratt duda de la citada aseveración del poeta portugués, no creyendo sea "la única en los autos que merezca crédito". ${ }^{37}$ Fija la fecha del referido Auto da Festa después de la de Templo de Apolo, pero sólo con unos cuantos meses de diferencia. ${ }^{36}$ Deja, pues, la situación de tiempo casi igual. No parece razonable el conde de Sabugosa al dar 1535 para el auto. ${ }^{39}$ Braacamp de Freire se inclina a creer que el gran lusitano nació en $1452 .^{\circ 0}$ Fitzmaurice Kelly se limita a senalar una época: entre 1452 y 1475," aunque en la versión

(29) A. F. G. Bell, Sobre O. de Patt: Gil Vieanfo, en Reviste de filologia Españolo, 1932, XIX, núm. 1, p. 84.85.

(30) Aubrey Bell, The Oxford Book of Portuguese Varse. $X I 1$ th century $-X X$ th century.

(31) Hermenegildo Giner de los Rios y Juan Givanel y Mas, Manual do literatura national y extranjera, antigua $y$ moderna. Litoraturas hispanas, especiales $y$ regionales (III Vols.. Madrid, Libreria de Vietoriano Sudrez, 1917, II), pag. 91.

(32) Aubrey Bell, Sobre O. de Pratt: Gil Vicento.... pp. B4-85.

(33) Moreelino Menéndez y Pelayo, Op, Cir., pdg. CLXVI.

(34) Aubrey Bell, Portugueso Literature..., p. 108, Nota 4.

(35) Gil Vicente, Auto da Fosla. Cita de Aubrey Bell en: Sobrt O. de Pratt..., p. 84-85.

(36) Aubrey Bell, Porfuguese Literature...., p. 108.

(37) O. de Pratt, Gil Vicente, citado por A. Bell en: Sobre I. de Prat1..., pp. $84-85$.

(38) Loc. cit.

(39) Loc. eit.

(40) Loc. eit.

(41) Jaime Fitzmaurice Kelly, Historia do la literatura española $4^{\circ}$ ed. corregida y aumentada, Madrid, Ruiz Hermanos, 1926), p\&g. 144. 
Inglesa de su obra dice: "He is generally supposed to have born about 1465." A2 Afirma De la Barrera: "Nació por los últimos años del siglo $X V$ cuando ya florecía y era célebre Juan del Encina." "3 Veamos a Merimée: "Nació probablemente el mismo año que Juan del Encina en 1469..." "\$4 Otra es la fecha que nos da don Hermenegildo Giner de Los Rios: $1485 .^{15}$

4. Padres. - Poco sabemos sobre los padres del insigne poeta portugués. Menéndez y Pelayo censura a los que pretenden hallar la solución a este problema en unos versns del Auto da Lusitaria, que leen así:

".................. . .
Nasceo mui baixo doutor.
Neto de um tamborileiro;
Sua mae era parteira,
E seu pae era albardeiro."

Si creemos esto, tendríamos que aceptar otros datos visiblemente fantásticos, de acuerdo con el crítico español.10 Este trae la versión del generalogista Alão de Morães, quien asevera que Gil Vicente era hijo de un orifice de plata de Guimaraens, llamado Martín Vicente. ${ }^{47}$ Bell parece no estar seguro si el nombre era Martín o Luis. ${ }^{40}$

Posiblemente nació de distinguida alcumia. De la Barrera dice: "Hijo de ilustres padres;" $\$$ Ticknor: "... Caballero portugués de noble cuna." dade nobilíssima."

5. Estudios. - Menéndez y Pelayo cita una rúbrica del Cancionero de Resende en la cual se llama a Gil Vicente Mestre Gil, "y esto indica que fue graduado de Universidad, probablemente en la facultad de Leyes." "Ticknor $^{63}$ y Fitzmaurice Kelly $^{54}$ se inclinan a creer esta probabilidad. De la

(42) Id., A New History of Spanish Literature (Londen, Oxford University Perss, 1926), p. 161.

(43) Cayetano de la Barrera y Leirado, Calálogo bibliogrffico y biográfico dol toalro anti. guo ospañol, desda sus crigenes hesta mediados del siglo XVIII (Madrid, Imprenta y estereotipia da M. Rivadeneyra, 1860), pág. 474. (44) Ernesto Marimes, Compendia de histeria do la literatura española. (Traducción del por el iraductor, México D. F., Libreria Hispania, 1931 pág. 62.

(45) H. Giner $d=$ los Rícs, Op. cit., psg. 91.

(46) Menéndez y Pelayo, Op. cil., pág. CLXVI, Notz 3.

(47) Lec. cit. Neto 2.

(48) Aubrey Bell, Portugueso Litoratura..., p. 109.

(49) C. de la Burrera, Op. cit., póg. 474.

(50) G. M. Ticknor. Histeria de is literztura española. (Iraducida al castellano, con adicio. nes y notas eríticas por D. Pascual Geyanges y D. Enrique Vedia. IV Vols., Madrid, Imprenta de La Publicidad a cargo de M. Rivadeneyra, 1851), pág. 296.

(51) Aubrey B=ll, Pertuguese Lilerature.... p. 103 (Citado par.....)

(52) Marcelino Menéndez y Pe!ayo, Op. Cis., pág. ClXVII.

(53) G. M. Ticknor, Op. cit., pdg. 296.

(54) J. Fitzmaurice Kelly, Historia do la literatura española..., pág. 144. 
Barrera, dice que "... dedicó al estudio de Jurisprudencia en la Universidad de Lisboa...;"5s igualmente D. Hermenegildo Giner de los Ríos asegura que "fue jurisconsulto." 56

Don Joaquin de Carvalho opina que, por el conocimiento de los escritos patrísticos que demuestra en algunas obras teatrales, Gil Vicente tal vez estudiaria en las universidades de Salamanca y la Sorbona; $;$ I. S. Révah rebate esto y expone que tal conocimiento pudo haberlo adquirido, no de primera mano en los textos latinos sino en textos religiosos en lengua portuguesa o española. ${ }^{58}$ Carolina Michaëlis de Vasconcellos cree que Gil Vicente fue "Iatinista sólo en el sentido, bastante limitado, de quien conoce los elementos de gramática latina y sabe traducir y retraducir textos sencillos; y que además ha sacado de s'us lecturas de textos romances algunas nociones de historia, mitología, $\mathrm{y}$ arte antiguo de Roma."s9

6. Su condición social. - "Su condición social es un enigma." nos manifiesta Menéndez y Pelay. ${ }^{\circ 0}$ Además de ser músico, poeta y autor, el crítico citado. ${ }^{61}$ Hurtado-Palencia ${ }^{62}$ y Aubrey Bell ${ }^{\circ 3}$ están de acuerdo con que fue actor. Bell se opone a la posición de O. de Pratt, quien no cree que nuestro biografiado fuese actor. Pratt, concluye que después de las primeras representaciones de sencillos autos Gil Vicente no hubiesse podido conservar su papel de actor "sem grave prejuizo das suas responsabilidades de organizador e dirigente... Quando muito o poeta reservarse-hía o papel de Argumentador". ${ }^{\text {st }}$ Menéndez y Pelayo cita unos versos de Andrés Resende, contemporáneo de Gil Vicente, para probar que éste fue actor:

"Cunctorum hinc acta Comoedia plausa

Quam Lusitania Gillo auctor et actor

(in aula

(55) C. de la Barrers, Op. cit., pág. 474.

(56) H. Hiner de los Rlos, Ip. sit., póg. 91.

(57) Joaquim de Carvalho, "Os sermōes de Gil Vicente c a arte de pregar," Estudos sobre a cultura portuguess do soculo XVI (Coimbra, 1947-1948), II, págs. 205-239.

(58) I. S. Róvah, Les sormons de Gll Vieente: en margo d'un opuscule du profossour Joaquim de Carvalho, Lisboa, 1949.

(59) Carolina Michä̈lis de Vasconcellos, Nolas vicentinas (Lisboa, 1949), pág. 220. (Cirada en: Gil Vicente, Obras dramúticzs cestellenzs, edición, estudio y notas de Th:mas $R$. Hart, Espasa-Calpe, Madrid, 1962, pág. XIII).

(60) M. Menéndez y Pelayo, $C_{p}$. cit., pág. CCXXI.

(6i) Loc. cit.

(62) Juan Hurtado y Angel Genzález Palencia, Op. cił., pág. 345.

(63) Aubrey Bell, Scbre O. de Prat: Gil Vicente..., pp. 84-85.

(64) Loc. cir., cirando \& 0 . de Pratl: Gil Vicontc. 
Egerat ante dicax atque inter vera

(facetus...

$\ldots \ldots \ldots \ldots \ldots \ldots \ldots$...........

Añade el eminente poligrafo español:

"pero se engañaría mucho quien le tuviese

por histrión de oficio o por un chocarrero vulgar

Nunca representó más que para los Reyes, de cuya casa era criado, y cuya protección no le

faltó en ninguún tiempo de su vida,

aunque es cierto que no le sacó de pobre.

Por eso decia en 1523:

E um Gil... um Gil... um Gil...

Hum que no tem nem ceitil,

Que faz os aitos a El Rei..."

Su posición puede inferirse por la influencia que ejerció sobre los frailes en el claustro de San Francisco, en Santarem; ellos, por consejos del poeta, deturvieron la ola de ira que se desató en el pueblo contra los judíos, después de un gran terremoto en 1531. El pueblo creía que el terremoto era um castigo por la tolerancia con que se trataba a los hebreos. Este gesto de Gil Vicente "a la vez que honra el carácter del poeta, prueba el respeto y la autoridad que gozaba entre sus contemporáneos." 67

Ticknor se refiere al poeta como "caballero portugués."

7. En la Corte. - La Corte de Portugal era en estos tiempos una de las más florecientes de Europa. Los lusitanos se habian adelantado a hacer exploraciones y conquistas en Oriente, Africa y América. Las riquezas traídas de lejanos territorios se invertían en mejoramiento artístico y utilitario de la Corte y de las ciudades.

Los Reyes se interesaban en la cultura. Juan II (1481-1495), D. Manuel el Venturoso (1495-1521) y Juan III (1521-1557) fueron figuras de relieve en muchos aspectos.

No sabemos con precisión cuándo arribó Gil Vicente a la Corte. Menéndez y Pelayo dice: Desde muy joven frecuentó el palacio y tomó parte en los solaces poéticos." ${ }^{\prime \circ}$ El problema

(65) M. Menéndez y Pelayo, Ip. cil., póg. CCXX. Nota I. ('La comedia a que Resendo alude es la Tragicomedja de Lusitznia, que fue repetida en Bruselas, en 1532, en casa del embajador portugués D. Pedro Mascarenhas.")

(66) Ibid., pág. CCXXI.

(67) Loc. cit.

(68) G. M. Ticknor, Op. cit., póg. 296.

(69) M. Menéndez y Pelayo, Op. cit., pág. CLXVII. 
de la identificación oscurece el asunto. Habia un Gil Vicente que ya para 1475 era moço de estribeira del príncipe D. Juan. ${ }^{70}$ José Cabedo de Vasconcellos, genealogista del siglo XVII, nos asegura que el poeta fue maestro de retórica del rey $\mathrm{D}$. Manuel, cuando éste era Duque de Beja. ${ }^{71}$

Es conocido el hecho de que siguió a la Corte a Evora, Coímbra, Thomar, Almeirín y otros lugares. Fue protegido de D. Juan II, de la esposa de éste doña Leonor, de D. Manuel y de D. Juan III. Nos dice Gassier: "Sous Juan II Gil Vicente obtint plus de faveur encore..."72

Representaba sus obras en la Corte, con mucha pompa y espléndido lujo, durante las fiestas reales y los saraos. Fueron aplaudidas por la familia real y los cortesanos. Según manifiesta Bell,

"He was... expected to render the idle courtiers muy ledos. To this purpose he was compelled to sadrle his plays with passages which for us have lost their savour and significance, but almost every line of which must have elicited a smile or a shout of laughter at the seroes."

Su actividad dramática cubre los años de 1502 a 1536. Marques Braga dice en relación con esto:

"E neste período de proficuo labor, de exuberante floração, que assistimos a evolução do seu talento artístico..."74

El 8 de junio de 1502, en el nacimiento del que luego sería Juan III, Gil Vicente representó en la cámara real, ante la Reina Madre doña María (nija de los Reyes Católicos) su famoso Monólogo del Vaquero (Auto de Visitaçam) que fue la primera pieza secularizada que en Portugal se representó, según opinaba el mismo autor "Asistieron el Rey D. Manuel, la reina doña Beatriz su madre, y la duquesa de Braganza su hija," dice Menéndez y Pelayo. ${ }^{75}$ Esta obra se compuso en castellano para halagar a doña María. El género agradó y

"la reina vieja doña Leonor, viuda de Juan II,

(70) Loc. cil., Nota 1.

(71) Aubrey Bell, Portuguese Lítorature.... pp. 109.110.

(72) Alfred Gassier, Le Thealre Espagnol (Deuxieme edition, Paris, Raul Ollendorff, 1898), p. 20.

(73) Aubrey Bell, Portuguese Litorature..., p. 128.

(74) Gil Vicento, Triunfo do Inverno (Edirado por Marques Braga, Lisbod, Imprensa Nacional, 1934), pág. VI.

(75) M. Menéndez y Pelayo, Op. cit., pág. ClXII. 
la cual parece haber protegido de un modo muy señalado a Gil Vicente, estimulándose en la composición de muchas de sus obras dramáticas, quiso que se repitiese el monólogo en los maitines de Navidad, pero como no tenía ninguna conexión con aquella fiesta, prefirió el poeta hacer un Auto pastoril castellano. Quedó la reina tan satisfecha que para el día de los Reyes le encargó otro Auto de los Reyes Magos.""7o

Tal fue el comienzo fausto de sus representaciones en palacio. En ellas se vertió todo el ingenio, la gracia y el saber artístico del poeta, quien asistía a su vez al espectáculo grandioso de las glorias nacionales que estaban en su cumbre.

Gil Vicente se hizo necesidad en todo acontecimiento real. Templo de Apolo fue representado en ocasión de la partida de la Emperatriz doña Isabel para Castilla, en 1526, para ser esposa de Carlos V. Näo d' amores tuvo oportunidad en 1527, para dar realce al recibimiento de doña Catalina en Lisboa. Cortes de Júpiter fue "más cólebre que ninguno otro por la pompa con que fue representado en las fiestas del casamiento de la Infanta Doña Beatriz, duquesa de Saboya, en 1519."'7 Asi podriamos continuar enumerando.

No sólo en obras teatrales se distinguió, sino en su habilidad para dirigir. Figueiredo nos cuenta que en 1520

"don Manuel le encargó la dirección de los festejos con que el Municipio de Lisboa celebraba la llegada de la Infanta doña Leonor, hermana de Sarlos V, que venía a ser la tercera mujer del Rey Afortunado."78

Como se ha probado, su antividad cortesana abarcó otros campos. Fue un orifice muy diestro al servicio de la reina viuda doña Leonor, y también mestre da balanca de la Casa de la Moneda de Lisboa, según consta en documento fechado el 4 de febrero de $1513 .{ }^{79}$ Sirvió como inspector de las obras de plata que se hacian en el Convento de Thomar, en el Hospital de Todos los Santos en Lisboa, y en Belem..$^{80}$

Los Reyes de Portugal, pues, fueron Mecenas de nuestro insigne biografiado, en igual forma que los Médici, los Sporza,

(76) Ibid., pág. CLXVIII.

(77) Ibid., pdg. CCXI.

(78) Fidelino Figueiredo, Op. cit., pág. 49.

(79) Aubrey Bell, Portuguase Lifersture..., p. 113.

(80) Ibid., p. 112. 
los Este y otros lo fueron para grandes artistas del Renacimiento italiano.

8. Casamiento e hijos. - Marques Braga, investigador vicentino, nos dice sobre el particular:

"Braacamp Freire documentou a vida de Gil Vicente e dos filhos do primeiro matrimonio con Branca Bezerra: Gaspar (?-1519) que parece ter estado na India e ter sido moço de capella, e Belchior (1504 ou 505-1552?), escudeiro. Do segundo matrimonio con Melicia (Belicia) Rodrigues, teve o poeta palaciano: Paula Vicente (1519-1576), Luiz Vicente e Valeira."

Se supone, según dice Braga, que enviudó de doña Blanca en 1514, y le escribió en epitafio ${ }^{22}$ muy significativo. Añade Bell:

"Some hold that he married his first wife, Branca Bezerra, in 1512, that he owned the Quinta do Mosteiro near Torres Vedras (a supposition no longer tenable), that the name of his second wife was Melicia Rodrigues, but we have no certainty as to this, nor as to the number of his children."

Esta última aseveración de Bell es muy cierta. Veamos. Menéndez y Pelayo menciona sólo una esposa, doña Blanca, y dos hijos, Luis y Paula, dudando de la existencia de Gil, debido a una leyenda, tildada te extravagante, de Manuel de Faria y Sousa. ${ }^{84}$ Mariscal de Gante menciona como hijos a Gil y a Paula ${ }^{85}$ De la Barrera cita a Luis, Paula y Gil. ${ }^{86}$ Bell se refiere a Blechior en relación con un documento sobre la fecha de la muerte del dramaturgo. ${ }^{B 7}$

(81) Gil Vicente, Triunfo do Inverno (Editads por Marques Braga...), p. X, Nota 1 .

(82) Ibid., p. X. Menéndez y Pelayo lo transeribe en la pógina cexxil, Nola 1, de la obra suya que hemps estado citando. Dice asi:

"Aqui jaz a mui prudento

Senhora Branca Bezerra

Mujer de Gil Vicente

Feifo terra."

(83) Aubrey Bell, Portuguese Literafure, p. 110.

(84) Menéndez y Pelayo, Op. cit., pág. CCXXIl. Manuel de Faria y Sousa, llamado por Menéndez y Pelayo "indigesio y crédulo e mpilador de tedo género de rumores $y$ patrañas: dice que el dramaturgo, ceicso del gran talento póticico de su hijo, lo envió a morir en destierro en la India. No es Faria y Sousa el único que nos habla de Gil. Hemos visto que do la Burrera y Mariscal de Gante lo mencionan. Este último, en la obra suya que citamos, página 476, dice que Gil "abrazó la carrera militor y pasó - servir en la India, donde murió en acción de gusrra." Añade a continuación: "Esto refiero Barbosa. Nuestro García Villanuevo Hugalde y Parro dico que este poeta, a quien llama Luis, compuso una comedia tifulada: los cautivos, y que celoso su padre del mérito que por ella descubría, lo envió "India, donde perdió la vida." Nos es, pues, Faria y Sousa el oxclusivo autor de la leyenda, como dice Marcelino Menéndez Y Pelayo.

(85' Jaime Mariscal de Gante, (Los aulos sacramentales desdo sus orígenes hasta mediados del siglo XVIII (Madrid, Bibliotecs Renacimiento, 1911) póg. 50.

(86) C. de la Barrera, Op. Cił., pág. 475.

(B7) Aubrey Bell, Porfuguese Literature..., p. 110. 
Los distintos críticos mencionados nos hablan sobre estos hijos y hasta nos dan datos biográficos. A los que más se refieren son a Paula y a Luis, lo que nos da a entender que sobre éstos hay plena seguridar. Ellos publicaron, según Menéndez y Pelayo, las obras de su padre en $1562 .^{\circ \circ}$ Paula era moza de cámara de la infanta doña María, tía del Rey $\mathrm{D}$. Sebastián. Se dice que ayudaba a su padre en la composición de sus obras. ${ }^{\circ 9}$ Gassier, al referirse a ella, dice: "Sa fille Paula, actrice tres belle te tres virtueuse, adorée de tout Lisbon... " Mariscal de Gante habla de ella como

"ilustre poetisa, diestra en la música, donosa actriz y autora de lindas comedias y de una gramática que intituló Arte de la lengua inglesa y holandesa." "9

Respecto a Luis, De la Barrera dice que fue poeta; de Gil, "competidor de su padre en la invención dramática." 92 Mariscal de Gante asevera que Gil "escribió el célebre Auto de $D$. Respecto a Luis, De la Barrera dice que fue poeta; de Gil, "competidor de su padre en la invención dramática." riscal de Gante asevera que Gil "escribió el célebre Auto de D. Luis de los Turcos."

Aunque no estamos seguros de la veracidad de algunos datos, por la oscuridad del asunto, creemos, en conclusión, que Gil Vicente dio hijos que fueron honra de la memoria de su padre.

9. Muerte. - Tampoco hay nada fijo en cuanto a la fecha de su muerte. Hay silencio sobre él desde 1536, año de la presentación de su última obra, Floresta de Engaños, y también del establecimiento de la Inquisición en Portugal. Esta coincidencia ha hecho pensar que el poeta, quien con espíritu erasmista criticaba aspectos mundanos de la Iglesia, fue silenciado por el Santo Ofjicio. Figueiredo habla de esto. ${ }^{94}$ Menéndez y Pelayo dice que el fallecimiento "no debió de ser mucho después de 1536," coincidiendo con Bell que manifesta: "there is reason to believe that hi died in this year (1536) or early in 1537." ${ }^{\circ 6} \mathrm{El}$ crítico inglés además se refiere a un documento sobre Belchior, supuesto hijo del poeta, para afir-

(89) M. Menéndez y Pelayo, Op. cił., pdg. CCXXII.

(89) Loc cit.

(90) A. Gassier, Op. cit., p. 20.

(9I) J. Mariscol de Gante, Op. cit., póg. 50.

(92) C. de la Barrera, Op. cif., pig. 475.

(93) J. Marisesl de Gante, loce cit.

(94) F. Figueiredo, Op. cil., p. 50.

(95) M. Menóndez y Pelayo, Op. cis., póg. CCXXIII.

(96) Aubrey Bell, Porfuguese Literature , p. 110. 
mar que éste murió antes del 16 de abril de $1540 .{ }^{97}$ Valbuena Prat $^{08}$ y Hurtado-Palencia ${ }^{99}$ dan 1539, con interrogación. Carolina Michaelis de Vasconcellos se atiene al período de 1536 a $1540 .{ }^{100}$ Ticknor, De la Barrera y H. Giner de los Ríos, sin detenerse a señalar el problema cronológico, no ponen reparos en decir que fue en 1557. Ticknor afirma que "consta que murió en 1557." "or De la Barrera escribe más:

"Habiendo pasado nuestro Gil Vicente a Evora con la Corte, murió allí año de 1557, con gran sentimiento de los príncipes y de todos los amantes de las Letras. Fue enterrado en el Convento de San Francisco de aquella ciudad, grabándose sobre el sepulcro un epitafio en verso, que tenía compuesto para sí y se halla inserto en sus obras." 102

10. Conclusión - Hay, pues, interorgantes sobre diversos aspectos de la vida y la muerte de este ilustre creador lusitano, cuya obra teatral - en portugués y castellano - se desenvuelve en refinado clima lírico y de quien ha dicho Menéndez y Pelayo: "Como autor dramático no tiene quien le aventaje en la Europa de su tiempo,"103 opinión que comparte el crítico inglés Aubrey Bell al considerarlo "the greatest dramatist before Shakespeare." 104 Su creación, que nos queda como valioso tesoro, hace viva y perenne su presencia en el mundo de las letras.

(97) Loc. cit.

(98) Angel Valbuena Prat, Literatura dramática española.... pág. 53.

(99) Jusn Hurtado y A. Gonź́lez Palencia, Op. cit., pág. 344.

(100) C. Michaëlis de Vasconcellos, Op. sit., págs. 14-15.

(101) G. M. Ticknor, Ip. cit., pág. 296.

(102) C. de la Barrero, Op. cit., p. 474.

(103) M. Menéndez y Pelayo, Op. cit., pág. CCXIII.

(104 Aubrey F. G. Beil, "Notes for an Edition of Gil Vicente; Rovuo Hispanique, 1929. ixxvil, p. 408. 